\title{
LA TEOFANÍA PROFANA EN LA OBRA POÉTICA DE VICENTE HUIDOBRO ${ }^{1}$
}

\author{
Sergio Pizarro Roberts \\ Universidad de Playa Ancha. Facultad de Humanidades - CEA \\ sergioto.pizarro@gmail.com
}

\section{RESUMEN / ABSTRACT}

\begin{abstract}
A través de una lectura global y diacrónica, este artículo problematiza el significado de la muerte en la poesía de Vicente Huidobro, constatando el surgimiento paulatino de un sujeto escatológico que emite su discurso desde ultratumba, sujeto inédito en la tradición poética chilena. La habilitación de la muerte en tanto lugar de enunciación da como resultado un discurso heterodoxo, respecto de las creencias cristianas, que es el de una teofanía profana en cuya configuración paradójica la figura del palíndromo es la clave para que este discurso del hablante huidobriano transite a través del umbral de la muerte.
\end{abstract}

Palabras clave: Vicente Huidobro, muerte, teofanía, heterodoxo, palíndromo.

Through a global and diachronic reading, this article problematizes the meaning of death in the poetry of Vicente Huidobro, establishing the gradual emergence of an eschatological subject that emits its discourse from hereafter, an unknown subject in the Chilean poetic tradition. The modification of death as a place of enunciation results in a heterodox discourse, regarding Christian beliefs, which is that of a profane theophany in whose paradoxical configuration, the figure of the palindrome is the key in order to pass this discourse of the Huidobrian speaker through the threshold of death.

KEYWORDS: Vicente Huidobro, death, theophany, unorthodox, palindrome.

$1 \quad$ El presente artículo se desprende de "Poéticas escatológicas heterodoxas en la poesía contemporánea chilena. Variantes de la resignificación de la muerte en la obra de Pablo Neruda, Gabriela Mistral, Pedro Prado, Vicente Huidobro y Nicanor Parra", tesis defendida en agosto de 2015 para optar al grado de Magíster en Literatura Chilena e Hispanoamericana en la Facultad de Filosofía y Educación de la Pontificia Universidad Católica de Valparaíso. El artículo es una transcripción adaptada del acápite correspondiente de dicha tesis. 
Si primeramente el hombre atisba al más allá y coloniza la invisibilidad, instalando en su discurso la posibilidad de una supravida, se convence, asimismo, de que hay momentos en que dicha invisibilidad toma contacto con la realidad visible en la que vive cotidianamente. Dichos momentos son catalogados como sagrados y, en la medida en que vaya transcurriendo el tiempo, esos momentos se irán alejando indefectiblemente para las generaciones posteriores, adoptando las características de un relato mítico.

Mircea Eliade instala el concepto de hierofanía, una categoría antropológica que, etimológicamente, implica la manifestación de lo sagrado (del griego hieros, sagrado y phainomai, manifestarse). A través de esta categoría se pretende demostrar que en la evolución del hombre primitivo, éste se va constituyendo paulatinamente en homo religiosus. La hierofanía es pues, la representación simbólica de un momento fundacional disuelto en el tiempo y que se pretende actualizar. En la medida en que transcurre el tiempo nos alejamos de aquel momento primigenio, de la advocación de la invisibilidad, y es preciso reconstituirlo: de ahí la razón de la hierofanía. Para las sociedades premodernas lo sagrado se muestra y según Eliade:

puede manifestarse en las piedras o en los árboles [...] no se trata de la veneración de una piedra o de un árbol por sí mismos. La piedra sagrada, el árbol sagrado no son adorados en cuanto tales; lo son precisamente por el hecho de ser hierofanías, por el hecho de "mostrar" algo que ya no es ni piedra ni árbol, sino lo sagrado (Lo sagrado y lo profano 15).

En ello va aparejada la paradoja que el mismo Eliade confirma, ya que al manifestar lo sagrado, un objeto cualquiera se convierte en otra cosa sin dejar de ser él mismo. Cuando se instala el concepto de lo sagrado surge inmediatamente, y por oposición, la categoría inferior de lo profano. Lo sagrado es equivalente a lo que confiere vida, a la potencia, a la realidad por excelencia, a lo que está "saturado de ser" (16), según Eliade, y si lo sagrado es real, lo profano representa lo opuesto, es decir, lo irreal. Para las sociedades arcaicas el mundo profano es un espacio desacralizado que requiere de lo sagrado para obtener realidad, justificación y eficacia. Lo sagrado insufla existencia real a lo profano que por sí mismo es vacuo e inconsistente.

Según lo anterior, se puede constatar que en la evolución espiritual de las sociedades premodernas el ser humano primero coloniza la invisibilidad y luego le asigna el poder para conferirle existencia útil a este mundo visible y profano a través de las manifestaciones sagradas que lo validan. Las sociedades 
modernas, por su parte, rechazan esta restricción de la existencia que impone la concepción premoderna y pretenden recuperar la realidad perdida en la cotidianeidad profana, sin necesidad de su ratificación a través de lo sagrado. La modernidad instala la idea de un cosmos completamente desacralizado.

Las vanguardias de inicios del siglo XX se perfilan como la fase crítica de la modernidad, y Vicente Huidobro (1893-1948) pertenece a este periodo. En esta fase de la modernidad, con un mundo ya desacralizado, se avizora que el "gran relato" del cristianismo no puede desacelerar el impulso secularizador. En el mundo moderno occidental lo que entra en crisis es la religión "que dejó intacta, aunque vaciada de su contenido explícitamente trascendental, la fe judeo-cristiana en el progreso histórico (camino a la salvación)" (Nial Binns 78). Esta crisis no hace sino intensificar la inquietud metafísica que deja la estela del vacío religioso, y la obra poética de Huidobro no es una excepción a esta tendencia.

Siendo parte del pensamiento moderno, Huidobro contiene en su obra poética la desacralización del mundo y la recuperación de lo profano como base ontológica de la realidad, sin necesidad de recurrir a la plataforma de lo sagrado para sustentarla. Sin embargo, si bien es un poeta profano, su inquietud metafísica lo lleva a indagar compulsivamente en la invisibilidad tanatológica con la intención de presentizar la manifestación de lo sagrado que ya se ha perdido en lo inmemorial de la humanidad. En la búsqueda de esa manifestación perdida se transforma en el artífice de ese mecanismo de rastreo y, finalmente, en la manifestación misma de lo sagrado al instituirse, en su obra emblemática El espejo de agua (1916), como "pequeño Dios" e "inventor de nuevos mundos".

La pretensión metafísica de encontrar la manifestación divina transforma su

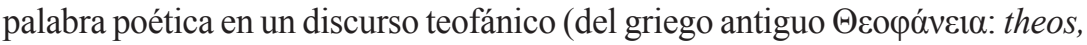
dios, y faino, manifestación, aparición), y la intención de actualizar dicha manifestación de lo sagrado a través de un lenguaje poético basado en la realidad sensible "profaniza" el mensaje de su experiencia religiosa. Con lo anterior se puede aseverar que el análisis de la evolución de la obra poética completa de Vicente Huidobro arroja la configuración de una teofanía profana, obteniéndose la reunión oximorónica, en el discurso del hablante huidobriano, de dos conceptos considerados tradicionalmente opuestos: la manifestación de lo sagrado y la mundanidad desacralizada. No es temerario sostener que casi la totalidad de la obra lírica y parte de la novelística del autor contienen una isotopía escatológica compulsiva que transmite una profunda inquietud 
metafísica, y que configura, más que un corpus, un opus poético escatológico coherente y sólido.

Desde los primeros libros del autor se detecta la referida preocupación metafísica a partir del léxico utilizado en los títulos Ecos del alma (1911), La Gruta del silencio (1913), Canciones en la noche (1913), Pagodas ocultas (1914) y Adán (1916)². La palabra muerte y sus derivados se repite más de cien veces en toda su obra, además de la reiteración permanente de términos como "alma", "cementerio", "eternidad", "sepulcro", "tumba", "ultratumba" y otras de índole semejante. No es por capricho que en el libro Altazor (1931) aparezca la palabra muerte repetida treinta y cinco veces.

El libro Ecos del alma, publicado en 1911, representa la faceta ortodoxoteísta del poeta, previa al desarrollo de su discurso heterodoxo-teofánico. Son recurrentes los versos que, en un tono piadoso, aluden a las figuras centrales del cristianismo; desde el título mismo de la obra, el poeta plasma su inquietud metafísica presentándola bajo la representación simbólica de un sonido inmortal que se repite indefinidamente. Lo que asombra al alma en este libro es lo que no tiene respuesta, lo irresuelto, aquello cuya explicación se desconoce; los "hondos misterios" (138) que serán la base del proceso de resignificación semántica que se inicia en el libro siguiente.

En el segundo libro, La gruta del silencio (1913), el poeta disminuye casi totalmente las alusiones al fervor teísta cristiano que se encuentran en Ecos del alma. Asimismo, en el poema "Coloquio II" el poeta se lamenta: "Alma, $[\ldots]$ / Te has vuelto una caverna" (140). En esta "caverna" o gruta del silencio, a la que hace referencia el título, el alma (que, en el verso recién citado, se ha convertido en una gruta o caverna) ya no recibe las repeticiones sonoras del eco teísta del primer libro. "Ecos del alma" se transmuta en "El silencio del alma". En este punto es donde comienza la resignificación de la muerte en la obra poética de Huidobro; resignificación que confiere a su dimensión escatológica el carácter heterodoxo. La gruta del silencio está dividida en dos partes. La segunda parte se titula "El libro de la meditación" y contiene, entre otros, cuatro importantes poemas desde la perspectiva de esta investigación, a saber: "El libro silencioso", "Cuando yo me haya muerto", "El terror de la muerte" y "Coloquios espirituales". Del poema "Cuando yo me haya muerto", destaco:

2 La investigación de la poética de Vicente Huidobro se sustenta en las obras completas contenidas en la edición Zig-Zag del año 1964. 
Mi alma se quedará mirando el cuerpo inerte [...]

Y por una ventana se escapará la muerte [...]

Mi espíritu irá siempre detrás de los que he amado [...]

Y después, cuando mueran los seres más queridos

Al lado de la Muerte los estaré aguardando,

Y qué goce tan grande cuando otra vez unidos

En los hondos misterios yo los vaya iniciando

(137, 138, la cursiva es mía).

Es notorio que el hablante no alude a las categorías cristianas ortodoxas del purgatorio, el paraíso, el infierno o el juicio de las almas. Tampoco se refiere a una instancia panteísta en la medida en que no hay disolución de la conciencia en un todo cósmico y armónico. Se mantiene la categoría cristiana del alma, pero sin la presencia de las divinidades de dicho credo. En esta indefinición adopta un giro que lo acerca más al ateísmo ${ }^{3}$. Se desprende que el hablante lírico huidobriano (más precisamente el alma lírica huidobriana) tiene la función de iniciar a otros en los hondos misterios escatológicos; solo él tiene esa función y no cualquiera. Estamos ante un primer indicio de la figura del "pequeño-dios" que aparecerá tres años después en El espejo de agua. Si bien son vagos los deslindes teológicos de este libro, el autor no tiene la intención de precisarlos desde una perspectiva ortodoxa.

Es en esta obra donde comienza la resignificación de la muerte que le confiere el carácter heterodoxo a la obra poética de Huidobro. Al quedar clara la posibilidad de que la muerte sea un lugar de enunciación factible la reconfigura semánticamente. Sin embargo, el alma-hablante huidobriana aún no está habilitada para emitir su discurso poético desde dicho lugar escatológico a pesar de que se prevé tal posibilidad. Se anticipa una teofanía.

\footnotetext{
"Teísmo y ateísmo son dos conceptos interrelacionados que afirman y niegan, respectivamente, la existencia de Dios. En principio lo que se afirma o rechaza es la existencia de la divinidad, uno o muchos dioses, no de alguno en concreto, como podría ser el de la concepción judeo-cristiana o la imagen de Dios que se ha desarrollado en la teoría filosófica. [...] Lógicamente, se puede rechazar que exista un dios concreto, el defendido por una religión o concepción filosófica determinada, y, sin embargo, no excluir que pueda existir lo divino. Generalmente, lo que se entiende por ateísmo es lo primero, que Dios no existe, y no simplemente rechazar un determinado concepto de divinidad. Esta es también la acepción vulgar del ateísmo y la que recoge el Diccionario de la lengua española" (Tamayo, Nuevo diccionario de teología 847).
} 
Las pagodas ocultas (1914) es la siguiente obra metafísica importante de Vicente Huidobro. Asimismo, es la primera obra en prosa poética del autor y es incuestionable la influencia que debió haber recibido de La casa abandonada, de Pedro Prado, publicada dos años antes (1912). A su vez, La casa abandonada es la primera obra en prosa poética de Prado y de enorme importancia en su trayectoria metafísica. Prado subtitula su libro con "Parábolas y pequeños ensayos" y Huidobro el suyo con "Salmos, poemas en prosa, ensayos y parábolas".

Las pagodas son templos budistas, es decir, estructuras arquitectónicas asiáticas de índole religioso. En el segundo verso de Las pagodas ocultas, el hablante metaforiza estos templos al señalar que "las almas son Pagodas Ocultas" (169). De esta manera, así como "ecos del alma" (su primer libro) se transmuta en "el silencio del alma" (su segundo libro), en esta ocasión el poeta desarrolla la idea de las "almas ocultas" (su cuarto libro). Del sonido del alma el poeta pasa a silenciarla para luego ocultarla. La figura del alma nuevamente espiritualiza al hablante huidobriano y el discurso es emitido desde esa categoría. Sin embargo, el alma-hablante sigue estando incapacitada (como en La gruta del silencio) para pronunciarse desde la muerte como lugar de enunciación. Se supone que el ser en estado de alma se corporiza al nacer y el alma-hablante huidobriana experimentará el mismo proceso vital. En un estado de súper conciencia el "alma lírica huidobriana" que nos ha hablado hasta el momento debe nacer como "hablante lírico huidobriano", y ese presagio contenido en Las pagodas ocultas se plasma en su siguiente libro Adán.

Adán (1916) es la primera obra poética de Huidobro escrita en verso libre. Nuevamente surge la incógnita acerca del posible efecto en Huidobro de otro libro de Pedro Prado, El llamado del mundo (1913), primer libro de poesía en verso libre publicado en Chile, que desarrolla el concepto de la catábasis en Lázaro.

En Adán, Huidobro reescribe la historia bíblica de la creación del mundo y del ser humano. Esta reescritura es heredera de la concepción científica-positivista del modernismo hispanoamericano por cuanto excluye la participación de Dios en el proceso de la Creación e infunde a la obra un carácter ateo con una posición expresamente acrática al no supeditarse a la autoridad divina del credo cristiano. Conviene detenerse en este punto en la medida en que el propio autor se confiesa panteísta en el referido prefacio de la obra en comento: "[e]n este poema he tratado de verter todo el panteísmo 
de mi alma" (223) 4 . Asimismo, en el poema "Caín y Abel", del mismo libro, desliza su supuesta adhesión a esta doctrina: "[e]l puro panteísmo / que no busca las cosas hacia afuera / sino en nosotros mismos" (251). Estos versos reflejan un real conocimiento de la doctrina del panteísmo y que constatan la gran repercusión que tuvo dicha doctrina en el pensamiento poético de principios del siglo XX en Chile tras el otorgamiento del Premio Nobel de Literatura a Rabindranath Tagore en el año 1913. Sin embargo, en el caso de Huidobro se constata una oscilación que cuestiona la efectiva adhesión del poeta a esa doctrina. En efecto, en el libro Temblor de cielo es posible verificar una explícita posición agnóstica que se distancia de sus anteriores posiciones teístas, ateístas y panteístas que dificultan la posibilidad de encasillar al autor en una sola de estas doctrinas ${ }^{5}$.

En definitiva, Adán se trata del nacimiento del hombre y ello no constituye sino la representación dramática del nacimiento de un nuevo hablante lírico.

\footnotetext{
"Panteísmo: concepción según la cual Dios es idéntico a todo. Puede verse como el resultado de dos tendencias: un intenso espíritu religioso y la creencia de que toda la realidad está unida de algún modo. El panteísmo ha de distinguirse del panenteísmo, la tesis de que Dios está en todas las cosas. Del mismo modo que el agua puede impregnar una esponja y estar así en toda la esponja sin ser idéntica a ella, Dios puede estar en todo sin ser idéntico a todo. Spinoza es el panteísta más distinguido de la filosofía occidental. Argumenta que puesto que la sustancia es completamente autosuficiente y sólo Dios es autosuficiente, Dios es la única substancia. En otras palabras, Dios es todo. Hegel también es a veces considerado panteísta, puesto que identifica a Dios con la totalidad del ser. Mucha gente piensa que el panteísmo es equivalente al ateísmo, porque cree que el teísmo requiere que Dios trascienda la realidad ordinaria, sensible, por lo menos en alguna medida. No es evidente que el teísmo necesite una noción trascendente o personal de Dios, y podría alegarse que la creencia de que lo es resulta de una visión antropomórfica de Dios. En la filosofía oriental, sobre todo en la tradición védica de la filosofía india, el panteísmo forma parte del rechazo del politeísmo. La aparente multiplicidad de la realidad es una ilusión. Lo que en última instancia es real o divino es Brahman" (Diccionario Akal de filosofia 733).

“Agnosticismo (del griego a-, 'no', y gnostos, 'conocido'), término inventado por Thomas Henry Huxley en 1869 para denotar la actitud filosófica y religiosa de quienes afirman que las ideas metafísicas no pueden ser refutadas ni demostradas. Huxley escribió: 'ni afirmo ni niego la inmortalidad del hombre. No veo ninguna razón para creerlo, pero, por otra parte, no veo manera de refutarlo. No tengo ninguna objeción a priori de esa doctrina'. El agnosticismo es una forma de escepticismo aplicado a la metafísica y especialmente al teísmo. Esta posición se atribuye a veces a Kant, quien mantuvo que no podemos tener conocimiento de Dios o de la inmortalidad, y tenemos, por tanto, que conformarnos con la fe. El agnosticismo no debe confundirse con el ateísmo, la creencia de que no existe ningún dios" (Diccionario Akal de filosofía 42).
} 
El tránsito que experimenta desde su categoría de alma lírica, a través de la cual nos habla el sujeto de la enunciación en sus primeras obras (ecos del alma, alma en silencio y alma oculta), a la categoría de hablante lírico como una nueva plataforma de enunciación. Como se señalaba anteriormente, el "alma lírica huidobriana", que nos ha hablado hasta el momento, nace en Adán como "hablante lírico huidobriano".

Por otra parte, la crítica que se ha ido asentando sobre la obra de Huidobro considera que efectivamente Adán dice relación con el nacimiento de un nuevo hablante lírico que supone la muerte del anterior. En su clásico ensayo "El Creacionismo pre-polémico" (1980), el profesor René de Costa señala que:

[d]urante su formación en Chile, Huidobro -al igual que Pedro Prado-había estado ensayando nuevas formas literarias en un esfuerzo por continuar la renovación modernista. Con intensidad aún mayor prosiguió este proceso en Europa; de tal modo que, al regresar a Santiago en 1919, estaba convencido de haber realizado la búsqueda de una renovada dicción poética. [...] Con la publicación de Horizon carré en París en diciembre de 1917 Huidobro cruzó definitivamente el umbral de la vanguardia (45).

En efecto, se da la particular coincidencia de que Adán fue publicada en el año 1916, fecha en que muere Rubén Darío. La influencia de este poeta es incuestionable en la obra de Huidobro. Tal influencia permite que en su obra se distinga entre una primera fase modernista, fuertemente influenciada por Darío, que culmina en El espejo de agua (1916), y una fase vanguardista, que se inicia en Horizon carré (1917), fuertemente influenciada por la tendencia cubista europea. En consecuencia, la muerte del hablante lírico modernista en Huidobro supone el nacimiento del hablante lírico vanguardista.

Esta explicación permite conciliar los dos acercamientos a la obra Adán: el primero, contenido en esta investigación, que alude a un tránsito de "alma" a "hablante" en un proceso metafísico que pretende instalar al sujeto lírico huidobriano en una muerte resignificada como lugar de enunciación, y el segundo, que señala el conocido tránsito desde el hablante modernista al vanguardista que ambiciona crear nuevos mundos a través de una nueva dicción poética. Se podría decir que el segundo acercamiento abarca al primero. En efecto, si el objetivo de Huidobro, explicitado en sus Manifiestos y en El espejo de agua, es el de "inventar mundos nuevos" a través de una nueva dicción poética, ello no se contrapone a la posibilidad de que, como resultado de dicho afán creacionista, la muerte sea semánticamente violentada 
y resignificada como lugar de enunciación a través de un hablante investido de la función sagrada de manifestarnos el más allá a través de la misma nueva dicción poética que inspira al creacionismo.

En 1916, el mismo año de la publicación de Adán, se publica El espejo de agua. Esta pequeña obra contiene solo nueve poemas entre los que destacan, para esta investigación, los dos primeros: "Arte poética" y "El espejo de agua". Los versos clave de "Arte poética" son:

Que el verso sea como una llave

Que abra mil puertas. [...]

Inventa nuevos mundos y cuida tu palabra;

El adjetivo, cuando no da vida, mata. [...]

Por qué cantáis la rosa, ¡oh Poetas!

Hacedla florecer en el poema; [...]

El poeta es un pequeño Dios (255).

La teoría poética creacionista de Huidobro, que abre las puertas a la posibilidad de otros mundos no contemplados en la realidad sensible de la naturaleza, no es obstáculo para que, en ese afán, se abra la posibilidad de que a la muerte se le conceptúe de una manera no tradicional. Si se puede resignificar la vida, también puede resignificarse la muerte, con la diferencia de que en el primer caso se altera el mundo físico y en el segundo se altera el mundo metafísico. En ambas situaciones estamos ante una alteración del discurso más que de la realidad. Con el creacionismo no se altera la naturaleza, sino la forma de significarla y con mayor razón tampoco se altera la muerte, sino la forma ortodoxa de otorgarle un significado.

Una prueba de que la teoría poética de Huidobro acoge esta posibilidad de resignificación escatológica la confiere la siguiente cita de su manifiesto "La poesía" (1925):

La Poesía está antes del principio del hombre y después del fin del hombre. Ella es el lenguaje del Paraíso y el lenguaje del Juicio Final, ella ordeña las ubres de la eternidad, ella es intangible como el tabú del cielo. [...] El poeta os tiende la mano para conduciros al más allá del último horizonte [...] más allá de la vida y de la muerte, más allá del espacio y del tiempo, más allá de la razón y la fantasía, más allá del espíritu y la materia (655-656).

El sujeto de la enunciación habilitado escatológicamente sufre mutaciones importantes en el íter poético de Huidobro: el alma lírica de las primeras 
obras de Huidobro sufre una metamorfosis y se convierte en hablante lírico, en Adán. A su vez, con la obra El espejo de agua vuelve a sufrir una mutación para transformarse en el pequeño Dios creacionista. Hay un coqueteo permanente con la metafísica por cuanto tanto el "alma" como el "pequeño Dios" espiritualizan al emisor del discurso lírico.

La paradoja de que un dios sea pequeño se complementa con la otra paradoja de que una teofanía sea profana y ambas son acogidas sin resistencia en la poética huidobriana. Como se trata de un dios pequeño, su expresión o discurso no alcanza la categoría sagrada de la manifestación de una divinidad superior; su manifestación o teofanía no alcanza siquiera a ser sagrada, es simplemente profana. Lo que está intentando el sujeto lírico es circunvalar a la muerte para encontrar en algún punto específico el umbral que le permita cruzar sus deslindes y asir prometeicamente la palabra escatológica, el discurso de ultratumba. Es importante señalar que si bien el sujeto de la enunciación está habilitado para conducirnos más allá de la muerte, en la obra El espejo de agua todavía no logra emitir su discurso desde ese lugar escatológico; está recién investido de la calidad de pequeño Dios.

En íntima conexión con "Arte poética” se encuentra el poema "El espejo de agua" en el que se destacan los siguientes versos:

Mi espejo, corriente por las noches,

Se hace arroyo y se aleja de mi cuarto.

Mi espejo, más profundo que el orbe

Donde todos los cisnes se ahogaron [...]

Es un estanque verde en la muralla [...]

De pie en la popa siempre me veréis cantando.

Una rosa secreta se hincha en mi pecho

Y un ruiseñor ebrio aletea en mi dedo $(255,256)$.

La crítica Ana María Cuneo en el análisis que hace de este poema expresa: "Interesante es enfrentar el título "El espejo de agua" con el de la obra inmediatamente posterior del autor: "Horizon carré". El primero se inscribe en el lenguaje de la tradición modernista; "Horizon carré", en cambio, es una metáfora creada" (67). Un horizonte cuadrado es una imagen creacionista en la que la naturaleza no se ve reflejada miméticamente, sino que es modificada en aras de una nueva realidad creada por el poeta: la cuadratura de su horizonte. En cambio, un espejo de agua es una imagen propiamente modernista porque no altera la naturaleza, sino que la repite y la embellece. Un estanque, un lago o poza de agua en remanso hacen las veces de espejo y el poeta lo que hace 
es constatarlo retóricamente. Sin embargo, y a pesar del tinte modernista del título, el poema contiene el germen creacionista.

"El espejo de agua" es un notable poema de transición, la bisagra fundamental en el estilo del autor y un hito importante en la trayectoria de su poética escatológica. Los primeros cuatro versos que se transcriben hablan miméticamente del espejo que se encuentra en la habitación del hablante con un tono indiscutiblemente modernista, pero en el momento en que dicho espejo "es más profundo que el orbe" y que en el quinto verso se transforma en "un estanque verde en la muralla" modifica de tal manera el objeto enunciado que lo altera esencialmente. Modifica tanto el reflejo que produce el espejo, al contener insólitamente todo el orbe, como las características normales de un estanque al colocarlo en posición vertical y transformarlo en espejo mediante un mecanismo creacionista. Además, el estanque es verde, por ende, sucio, turbio y difícilmente puede reflejar los objetos de la habitación para cumplir su función mimética. Finalmente, los últimos dos versos que he transcrito inventan una situación que se aleja semánticamente de las palabras que la conforman y solo puede existir en el poema: la rosa que se hincha en el pecho del hablante y el ruiseñor ebrio que aletea en su dedo. Son los primeros dos versos en la obra huidobriana que plasman una dicción creacionista al alejarse del tono mimético que se utilizaba en su trabajo anterior.

El creacionismo es un mecanismo verbal importante para que el sujeto de la enunciación, convertido en pequeño Dios, pueda seguir buscando la fórmula que le permita emitir su discurso desde la muerte. Si reconocemos que la muerte es un lugar intrínsecamente poético por tratarse de un mundo puramente verbal sin comprobación empírica, las "mil puertas" que ofrece el creacionismo para indagar la realidad tangible pueden ser infinitamente mayores para indagar en el más allá.

Horizón carré (1917) es el libro inaugural de la vanguardia huidobriana y fue escrito en francés. Es en esta obra donde Huidobro comienza su fase creacionista propiamente tal con un texto y un lenguaje revolucionarios. Sin embargo, en esta obra el hablante recién está incursionando en sus "nuevos poderes" para indagar en la alteración de la realidad palpable y no realiza incursiones escatológicas. La innovación creacionista de Horizon carré también se percibe en los otros libros franceses de Huidobro, Tour Eiffel (Torre Eiffel) y Hallali, poeme de guerre (Halali, poema de guerra), ambos publicados en 1918. La fecha de publicación no es irrelevante porque en 1918 termina la Primera Guerra Mundial. Al efecto hay que recordar que Huidobro parte a Europa con su familia en 1916 para vivir en Francia durante aproximadamente 
diez años y llega en plena Primera Guerra Mundial (1914-1918). Se trata de un hecho no menor en la línea de esta investigación ya que esta experiencia de vivir la guerra tan directamente acerca al poeta a la muerte en circunstancias mucho más intensas de lo que podría haber ocurrido en un periodo de paz.

Algo similar ocurre con Ecuatorial (1918), obra que inaugura la vanguardia en lengua española y a la que se pueden aplicar las mismas observaciones técnicas, de forma y fondo, correspondientes a Horizon carré. Asimismo, la temática de la guerra también está fuertemente arraigada a esta obra donde figuran palabras modernas o de índole militar como aeroplanos, locomotoras, zepelines, soldados, submarinos, obúses, trincheras, etc. Sin embargo, y siguiendo el orden de lectura de esta investigación, en esta obra de corte creacionista, el discurso del pequeño Dios sigue indagando en la creación de nuevas realidades, pero no incursiona en el tema de la muerte como lugar de enunciación y en su calidad de sujeto emisor de un discurso escatológico.

Los hermosos Poemas árticos (1918) y los poemas franceses Automne régulier (Otoño regular) y Tout a coup (De repente), ambos de 1925, continúan la senda del creacionismo (de la vanguardia con mayor exactitud), pero no ofrecen mayores indicios a nuestra línea de investigación de la resignificación de la muerte que ameriten ser destacados.

Como se desprende de este análisis, la importancia fundamental que ha tenido la poética creacionista que se inaugura en 1917 con Horizón carré no ha dado resultados satisfactorios al hablante huidobriano en su esfuerzo para colonizar la invisibilidad de la muerte e instalarse en ella como sujeto de la enunciación con el objeto de trasmitirnos su particular teofanía. Tampoco le han ayudado mucho las continuas mutaciones de su calidad de sujeto lírico (alma-hablante-pequeño Dios). Han de pasar catorce años para que con la publicación de Altazor, en 1931, se logre la transfiguración del hablante huidobriano.

Altazor es un poema largo y está dividido en un prefacio y siete cantos. "Nací a los treinta y tres años, el día de la muerte de Cristo" (365). Este primer verso del poema nos enfrenta a una cuarta transformación del hablante lírico. El pequeño Dios ahora tiene nombre y casi dos mil años de edad y se refiere a la muerte de una manera mucho más intensa que en las obras anteriores. En efecto, la palabra "muerte" se repite más de treinta y cinco veces sin contar las otros vocablos derivados de lo tanatológico que abundan en el texto. Esta primera frase le da a la obra, desde el inicio mismo, un carácter heterodoxo al insinuar que Altazor es una especie de continuador de Cristo, otorgándole al personaje lírico de este poema un rol metafísico y trascendente. 
El prefacio de esta obra es fundamental para comprender la evolución escatológica del hablante al ofrecer un escenario aéreo que permite desplazamientos ascendentes y descendentes del sujeto que va a enfrentarse a un cruce de umbral en una dimensión que, por metafísica, es etérea. Cuando Altazor coge su paracaídas expresa: "[h]e aquí la muerte que se acerca como la tierra al globo que cae", y luego agrega: "ahora mi paracaídas cae de sueño en sueño por los espacios de la muerte" (365). Con ello se pone de manifiesto la diferencia de este texto con los primeros anuncios escatológicos que se dan en La gruta del silencio cuando el hablante se refiere en dicha obra primeriza a lo que ocurrirá "cuando él se haya muerto", es decir en un futuro lejano e impreciso. En el prefacio de Altazor se deja en claro que el momento del enfrentamiento con la muerte ha llegado: "[m]i paracaídas empezó a caer vertiginosamente. Tal es la fuerza de atracción de la muerte y del sepulcro abierto." [...] "ruedo entre las nubes de la muerte." (366). En este trance rápido, Altazor, en su calidad de pequeño Dios, va sufriendo alteraciones que lo transforman en una especie de vidente preclaro: "Lo veo todo, tengo mi cerebro forjado en lenguas de profeta" (367), y exclama: "[a]h mi paracaídas, la única rosa perfumada de la atmósfera, la rosa de la muerte, despeñada entre los astros de la muerte" [...] "[a]bre la puerta de tu alma y sal a respirar al lado de afuera" (368).

El canto I contiene las meditaciones metafísicas de este nuevo hablante (pequeño Dios y profeta) ante el trance mortal que experimenta. En estas meditaciones el hablante se cuestiona la doctrina escatológica ortodoxa del cristianismo, pone de manifiesto la crisis espiritual que sobrecoge al sujeto moderno y aborda la necesidad de replantear el enfoque metafísico a través de una resignificación de la muerte que adquiere ribetes heréticos:

Abrí los ojos en el siglo

En que moría el cristianismo [...]

¿Y mañana que pondremos en el sitio vacio?

Pondremos un alba o un crepúsculo

¿Y hay que poner algo acaso? [...]

Morirá el cristianismo que no ha resuelto ningún problema

Que sólo ha enseñado plegarias muertas

Muere después de dos mil años de existencia

Un cañoneo enorme pone punto final a la era cristiana

El Cristo quiere morir acompañado de millones de almas

Hundirse con sus templos

$\mathrm{Y}$ atravesar la muerte con un cortejo inmenso [...]

(371, la cursiva es mía). 
El poema se refiere a un "sitio vacío" que hay que rellenar y "plegarias muertas" que deben ser reemplazadas por otro discurso. La muerte es un lugar que el cristianismo ha dejado vacío y debe ser resignificado mediante el discurso emitido por un sujeto habilitado para enunciarlo ${ }^{6}$. En este canto se insta, y cada vez con más insistencia, al acercamiento del hablante hacia la muerte: "[b]ebamos la tímida lucidez de la muerte / la lucidez polar de la muerte / canta el caos al caos que tiene pecho de hombre / llora de eco en eco por todo el universo" (372). La muerte es caos, es desintegración $\mathrm{y}$, en consecuencia, es desestructuración semántica. La muerte implica la pérdida de la estructura biológica del ser que la experimenta y, en el caso del hablante lírico, la desestructuración de su voz en un proceso crítico que es considerado como una necesidad primordial para el cambio que impone la modernidad: "[1] a conciencia es amargura / la inteligencia es decepción / Sólo en las afueras de la vida / se puede plantar una pequeña ilusión” (375).

El proceso no está exento de pesar y angustia y el hablante se pregunta: “¿Por qué soy prisionero de esta trágica busca? / [...] / poliforme angustia anterior de mi vida / y que la sigue como una marcha militar / y que irá más allá / hasta el otro lado de la periferia universal / [...] / animal metafísico cargado de congojas" $(376,378)$. Además de angustiante, el proceso no es lento, el largo canto I machaca con insistencia la idea de la inminente transfiguración: "[y] voy a andando a caballo en mi muerte / voy pegado a mi muerte como un pájaro al cielo / voy pegado a mi muerte / voy por la vida pegado a mi muerte / [...] / soy protesta y araño el infinito con mis garras" (378).

Avanzado el canto I el proceso de desintegración comienza a acelerarse:

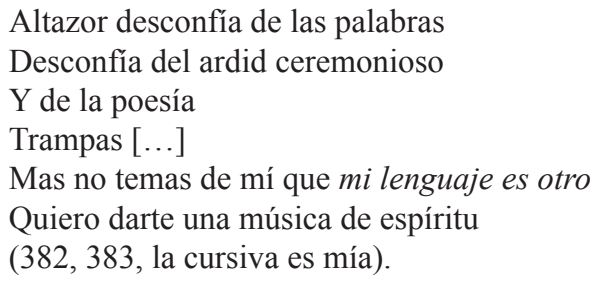

Se precipita el paracaídas de Altazor hacia la desconfianza de las palabras, hacia el silencio caótico y, por su intermedio, hacia otro y nuevo lenguaje.

6 El prólogo de Oscar Hahn a la edición de Altazor, publicada por Editorial Universitaria, ahonda en la indiscutible contribución que El anticristo de Nietzsche aporta a la configuración de dicho personaje huidobriano. 
En el canto III se inicia un vertiginoso proceso de inversión semántica como resultado de la presión desestabilizadora a la que se somete el hablante huidobriano en la caída. El significado de las cosas es violentamente afectado como un espejo que ha enloquecido en su función mimética: "[1]a flor se comerá a la abeja / [...] / conducirá el rebaño a su pastor / [...] / y el árbol se posará sobre la tórtola" $(390,391)$.

El eje central de Altazor y, en definitiva de este artículo, es el canto IV del libro. En este canto y sin "tiempo que perder" (394) el hablante ya no solo altera la sintaxis del discurso, como lo hace en los versos citados del canto III, sino que fractura la construcción del signo lingüístico a través de la figura de la jitanjáfora: "[a]l horitaña de la montazonte / la violondrina y el goloncelo / descolgada esta mañana de la lunala / se acerca a todo galope" (398). La caída irrefrenable y el acercamiento al umbral de la muerte han provocado desajustes en la estructura del lenguaje, comparable a la desorganización molecular que afectaría a la materia atravesando un agujero negro en el espacio. El eje gravitacional de Altazor se concentra en la parte final del canto IV:

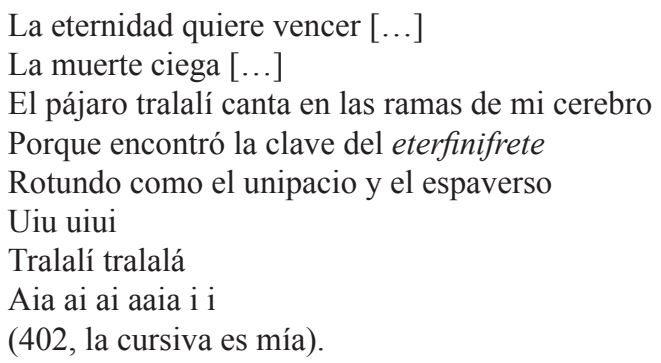

El pájaro tralalí, es decir el hablante huidobriano, encuentra "la clave del eterfinifrete", palíndromo que, como se sabe, es una palabra que puede ser leída en ambas direcciones. En este caso dicha palabra es el resultado de la combinación de los vocablos "eternidad", "finitud" y "eternidad" invertida. El sujeto proviene de la eternidad de su preexistencia, ingresa a la vida para enfrentarse con la finitud que le provoca la muerte y luego accede nuevamente a la eternidad de su postexistencia.

El hablante encuentra la clave para que su discurso entre y salga de la muerte a través de la figura palindrómica. Con ello, la resignificación de la muerte en la poética de Huidobro se explica en que todo discurso que entra al más allá lo hace con el riesgo de sufrir una descomposición semántica que no es otra cosa que la aplicación del método creacionista a una realidad de ultratumba. 
Se trata de una resignificación escatológica que opera en el plano discursivo, en la que toda estructura semántica que atraviesa el umbral de ultratumba sufre una alteración de su composición, y el concepto mismo de eternidad, por ejemplo, vuelve invertido, es decir, alterado de una manera que escapa a la lógica discursiva de la vida. Lo mismo ocurre con el espacio y el universo que vuelven con sus estructuras lingüísticas intercambiadas seguidas de una serie de vocales y consonantes que semejan fragmentos dispersos de palabras destruidas que vuelven en desorden (unipacio y espaverso).

Los cantos siguientes de la obra son una constatación de la transfiguración que ha sufrido el hablante huidobriano como pequeño Dios y de las posibilidades que se le presentan como sujeto de la enunciación. Ha llegado el momento en que al fin puede transmitir su discurso desde la muerte mediante un texto que se ha convertido en una teofanía profana.

En esta "odisea funeraria", como la llama Oscar Hahn, se percibe un justificado entusiasmo en el hablante ante la llegada del tan esperado momento cuando exclama en el canto V: "[a]quí comienza el campo inexplorado / [...] / [h] ay un espacio despoblado / que es preciso poblar / de miradas con semillas abiertas / de voces bajadas de la eternidad" (402-403). Repite majaderamente la frase "se abre la tumba" como un niño ansioso por mostrar lo que ve al fondo de la misma. "Festejamos el amanecer" espeta el hablante, "nos frotamos la manos y reímos / nos lavamos las manos y jugamos / el horizonte es un rinoceronte / el mar un azar" (407-408). La extensa anáfora del molino semeja la curiosidad lúdica de un niño que está aprendiendo a hablar. Brotan más jitanjáforas, cacofonías, anadiplosis, aliteraciones y otros recursos fonéticos que denotan la novedad de un lenguaje nuevo para el hablante.

Con esta transfiguración el hablante huidobriano experimenta una quinta mutación en el canto VII para convertirse en "eternauta" e "infinauta" (422423). Altazor es un pequeño Dios habilitado para navegar en la eternidad y el infinito, para ir y volver palindrómicamente de la muerte con su discurso teofánico.

Finalizado el análisis del poema, vale la pena señalar que la crítica ha ofrecido múltiples interpretaciones a esta obra ${ }^{7}$. Al respecto, considero

7 A modo de ejemplo, Hugo Montes, en su ensayo "Altazor a la luz de lo religioso" (1981) sostiene que "la gran línea seguida por el poema no es otra que la búsqueda de una nueva palabra creadora” pero que "[e]stamos lejos de esa palabra todavía. Altazor sigue debatiéndose en la angustia de su caída, que llega a convertirlo en Lucifer, el ángel caído, 
que la dificultad en el ejercicio radica en su intento de analizarla en forma aislada cuando debiera hacerse en forma conjunta con el resto de la obra huidobriana. Si en el análisis no se rescata la búsqueda metafísica incesante del autor en las obras anteriores y posteriores a Altazor, y que tiene como resultado una poética heterodoxa de la muerte, el tránsito de Altazor en su calidad de eternauta queda como un misterio sin resolver y, en el peor de los casos, como un sinsentido.

En 1931, el mismo año de publicación de Altazor, Huidobro publica otro poema largo, esta vez en prosa, titulado Temblor de cielo. Al igual que Altazor, este poema se ciñe a un eje temático que, en este caso, es básicamente una reescritura del clásico medieval Tristán e Isolda. El tema de la obra es una conocida historia de amor y tiene un evidente sesgo autobiográfico (la obra es coetánea al bullado matrimonio de Vicente Huidobro con Ximena Amunátegui). El objetivo al destacar este eje temático se debe a que el poema, desde el título mismo, no lo explicita. En efecto, se podría decir que la obra completa es un largo y complejo discurso metafísico del hablante y que, por primera vez en el recorrido del opus huidobriano, dicho hablante no está solo, ya que viene acompañado por Isolda, un personaje que comparte las mismas visiones metafísicas: "[s]olamente Isolda conoce el misterio" (426).

El poema está escrito en segunda persona y el hablante se dirige, por una parte, a Isolda, para hacerla partícipe de su experiencia metafísica y, en otras ocasiones, al "niño terrestre", es decir al ser humano, para excluirlo de dicha experiencia. Ese hilo conductor es importante porque el creacionismo del poema bordea el hermetismo con imágenes que, en ocasiones, están muy distanciadas entre sí y que dificultan la lectura. El contenido metafísico de la poética escatológica de esta obra tiene más puntos de interés que la trama de amor para los efectos de esta investigación, lo que se plasma al inicio del texto en los versos que transcribo:

embrujador del mundo" (38); el ensayo "Altazor: hacia una verticalización de la épica” (1979), de la profesora Berta López, desarrolla los argumentos que sustentan la renovación épica (de horizontal a vertical) de la obra Altazor; el artículo “Altazor de Vicente Huidobro" (1965), del crítico Jaime Concha, alude a la unidad de experiencia que debe considerarse en esta obra, una trayectoria que vendría a ser "un itinerario del alma que pasa por diversos estados" y que supone la "creación de un personaje lírico" y "su desplazamiento en un espacio imaginario" (1586); y el ensayo del profesor Cedomil Goic "Altazor, de Vicente Huidobro" (1970) destaca el sentido multívoco del viaje en paracaídas de Altazor. 
El Padre Eterno está fabricando tinieblas en su laboratorio y trabaja para volver sordos a los ciegos. Tiene un ojo en la mano y no sabe a quién ponérselo. $\mathrm{Y}$ en un bocal tiene una oreja en cópula con otro ojo.

Estamos lejos, en el fin de los fines, en donde un hombre colgado por los pies de una estrella se balancea en el espacio con la cabeza hacia abajo (425).

Indudablemente el hablante huidobriano, transformado en eternauta, se sitúa en el más allá como lugar de enunciación y desde ese lugar emite su discurso. Es más, se encuentra presenciando el acto divino mediante el cual Dios recopila desde el caos original los elementos para su constante creación. Se sitúa en un lugar y tiempo imposibles para una codificación lógica de esta vida terrena. Luego del arrebato que experimenta en Altazor, el tono en Temblor de cielo es menos extático; ha superado el trance y puede emitir su discurso en un tono más calmado. El hablante huidobriano devela el misterio que se esconde en el cielo y el título de la obra no es más que una constatación del remezón telúrico que el hablante ejerce sobre el más allá para obtener los elementos de su propio discurso escatológico.

"Entonces llega la hora de la transfiguración" (435): el hablante huidobriano vuelve a insistir en su nueva calidad de sujeto de la enunciación habilitado para emitir su discurso desde la muerte una vez traspasado el umbral palindrómico descrito en Altazor. En su discurso le dice a Isolda:

Soy lento, lento para morir.

No temo a la nada ni le temería aunque no tuviera la seguridad de seguir en mi eco, de seguir intangible rodando de eco en eco.

Isolda, tú has de encontrarme aún varias veces en muchos caminos de la eternidad. [...]

Mirad el muerto que se levanta en alta mar. Oíd la voz del muerto que se yergue en su sudario de olas. [...]

Oíd, oíd la voz de los muertos.

La gran voz de los abuelos, [...] y que demora años y siglos en llegar a la superficie y más años y más siglos en encontrar una garganta preparada.

La garganta poderosa que sea como una trompeta. La trompeta de las edades. La trompeta de todos los que han sufrido, de todos los que han temblado en sudores de sangre sobre el terror o el desaliento, la trompeta de todos los dolores, de todos los rencores, de todas las venganzas. [...] Por mi garganta la tiniebla vuelve a la $\operatorname{luz}(445,446)$. 
El hablante huidobriano cumple la promesa de las primeras obras y se transforma en guía o iniciador en la muerte. Su "eco del alma" es ahora la clara voz de ultratumba de un pequeño Dios, de un eternauta que recorre los "caminos de la eternidad". Su voz de muerto se yergue y absorbe, como una garganta poderosa, la voz de los abuelos, de los antepasados y de toda la humanidad sufriente. Su garganta está preparada para que la tiniebla vuelva palindrómicamente a la luz -"En la garganta del poeta el universo busca su voz, una voz inmortal" ("La poesía” 655)-.

Sin embargo, el poeta formula en esta obra una novedosa distinción. El discurso está dirigido alternativamente a dos destinatarios: a Isolda y al niño terrestre. Hasta el momento el autor desarrolla la capacidad del hablante huidobriano para transfigurarse en hablante lírico escatológico y poder emitir su personal teofanía. Solo dicho hablante tiene esa capacidad y su discurso emitido desde la muerte provoca una poética tanatológica heterodoxa. El resto de los seres humanos, salvo Isolda, han sido excluidos de esta posibilidad y no han sido siquiera partícipes de la progresiva evolución del hablante en el opus poético del autor. Es una experiencia exclusiva del hablante en el poema y recién en este libro se menciona, por primera vez, la muerte común de todos los seres humanos en términos no muy auspiciosos.

Con un tono de evidente superioridad se dirige apostróficamente a los seres humanos como "niños terrestres", como "salvajes" y les espeta: "[n]o es para vosotros el panorama del secreto naciente. ¿Qué sabéis vosotros de los encuentros de la eternidad?" (432). Y más desesperanzador aún, agrega: "[y] ese juego que habéis creído que es el juego de la vida, no es sino el juego de la muerte. [...] No otra cosa sois que la muerte sobre la muerte. Contempla el gesto de espasmo de aquella que se muere en la muerte. [...] Así, pues, atraviesas la vida encerrada adentro de la muerte" $(438,439)$. Esta aseveración encierra un profundo agnosticismo que luego se ve atenuado por una alternativa algo más panteísta, cuando se dirige histriónicamente a las "señoras y señores", expresándoles que: "[e]stáis allí en esa interminable posición en que quedáis después de haber bebido el vaso de infinito que destila el vacío y que os convierte en ceniza respetable de antepasado inmemorial. De todas esa cenizas puede el azar hacer un astro nuevo" (446). Después de la muerte, por ende, viene el vacío y una remota posibilidad de convertirse en polvo cósmico.

El concepto del vacío agnóstico de la muerte en el ser humano se ve reforzado en la última parte del poema: 
[... Nada se gana con pensar que acaso detrás de la muralla abstracta se extiende la zona voluptuosa del asombro.

No, no encontraréis al anciano sentado sobre las rocas de la nevazón eterna, sonriendo sin dureza y rodeado de héroes meditativos como palmeras.

[...] Sólo el ataúd tiene razón. La victoria es del cementerio. El triunfo sólo florece en el sembrado misterioso.

Así fue el discurso que habéis llamado macabro sin razón alguna, el bello discurso del presentador de la nada (447).

Temblor de cielo es el libro que disuelve la dicotomía vida/muerte y, como consecuencia, provoca una inevitable resignificación escatológica. Altazor es el preámbulo de la inversión semántica contenida en aquel libro. El hablante lírico que emite su discurso desde la muerte enrarece los límites y proyecta a la vida como invasora de la muerte $y$, a la inversa, el agnosticismo aplicable a la muerte de todos los seres humanos, proyecta a la muerte como invasora de la vida -"[y] ese juego que habéis creído que es el juego de la vida, no es sino el juego de la muerte" (438) -.

En el ensayo "Modernidad y fragmentación de la conciencia en Temblor de cielo" (2003), Orlando Jimeno explica:

Si la muerte, mitema recurrente en Temblor de cielo, constituye para el occidental un escándalo metafísico, se debe a la racionalización que introducen los dogmas, antes que ésta se integre a la periodicidad vital. La muerte no es escisión, es la razón la que produce la dicotomía subjetividad/mundo.

La tragedia metaempírica de la muerte es la de una temporalidad abolida en una eternidad previamente definida como concepto.

Para el "primitivo" como para el poeta morir es vivir a un nivel más alto- (1465).

En definitiva, la resignificación tanatológica en Temblor de cielo reemplaza la concepción teísta por una poética escatológica heterodoxa y revolucionaria en la que se desplaza el lugar de enunciación y permite al hablante lírico emitir su discurso "desde" la muerte y no "hacia" la muerte.

La última etapa de esta lectura diacrónica del opus poético huidobriano se aboca al análisis de los dos últimos libros de poesía publicados en vida por el autor el año 1941 y que se titulan Ver y palpar y El ciudadano del olvido. Transcurrirán diez años entre la publicación de Altazor y Temblor de cielo, en 1931, y los dos últimos libros antes referidos. 
Ver y palpar se publica en plena Segunda Guerra Mundial y nuevamente el autor se va a enfrentar de una manera más directa con la muerte con ocasión de este segundo conflicto mundial. Ello se refleja en esta obra al constatar que la palabra muerte y sus derivados se repiten cuarenta y un veces en todo el poemario (supera a Altazor). Por otra parte, el mismo autor nos da las señales para que comprendamos esta obra como continuadora de las anteriores al mencionar entre sus versos a Altazor y al referirse a un anterior temblor de cielo. El poeta vuelve a recalcar el hecho de que Altazor ha sufrido una mutación en su calidad de pequeño Dios, una transfiguración que lo convierte en eternauta e, igual que en Temblor de cielo, emite su discurso desde la muerte, habiendo ya traspasado el umbral palindrómico. En efecto, se nos repite que Altazor "se fue de su carne al viento estupefacto", es decir, se fue de la vida alojada en su carne hacia el viento estupefacto de la muerte. El hablante lírico, en esta obra y la siguiente, se verá incluso más imbuido en su calidad de hablante escatológico que en la anterior Temblor de cielo. Se encuentra más solitario, sin Isolda y sin seres humanos a quienes dirigir la palabra. Incluso empieza el libro despidiéndose de todo ("Hasta luego"). Comienza a profundizar su estadía en la muerte como lugar de enunciación y a distanciarse del umbral palindrómico. La dicotomía vida/muerte se torna aún más confusa: "[1] as palabras vivas bailan ante la muerte muerta" (457). La referida dicotomía incluso es disuelta en la fusión de las palabras "muerte" y "vida" en el poema "Canción de la muervida":

\author{
Mi cabeza por delante es un señor vivo \\ Y por detrás es un señor muerto \\ Los muertos han perdido toda confianza \\ En los cimientos de nuestras casas y de nuestras lenguas [...] \\ Qué podemos decirles \\ Ellos suben sobre el tejado de la eternidad [...] \\ Están desterrados de la tierra y encielados en el cielo \\ Los vivos alargan su ciprés $[\ldots]$ \\ Suben cantando hasta el piso de la muerte \\ Hablan con una lengua adormecida desde mucho tiempo \\ Son póstumos como los ecos de la flor del trueno (475).
}

El hablante sumido en un lugar de enunciación como la muerte pierde los referentes cronológicos, espaciales y semánticos. Se ve inmerso en una peligrosa libertad sin control lingüístico y su voz se torna cada vez más compleja para el receptor de su discurso que se sitúa en la vida como lugar de recepción. El paso del flujo discursivo a través del umbral palindrómico 
decodifica el mensaje. El significado en la muerte es otro que en la vida y la comunicación se dificulta. El discurso emitido desde la muerte va resultando cada vez más hermético para el receptor en la vida y eso es lo que ocurre en estas últimas obras del opus huidobriano. Se configura lo que se ha denominado la fase hermética de su obra y que se comprende con mayor claridad a la luz del contexto de la resignificación escatológica que se propone en esta investigación. En otro poema titulado "Las voces preciosas" el hablante que nos habla desde la muerte se describe:

Hay un recién muerto que aprende a andar en el más allá [...]

El muerto nuevo ensaya sus piernas

A la salida de la caverna

Ensaya su garganta en una lengua de vapores

Porque siente la semilla que brota al interior

$\mathrm{Y}$ tras sus pasos los mundos caen en ruinas $[\ldots]$

Hay tres veces la vida y la muerte

$\mathrm{Y}$ ese gran caos de palabras ciegas buscando una garganta $[\ldots]$

El mendigo del infinito [...]

Se va con su caverna

Con su recién nacido y su recién muerto $(492,493,494)$.

Al igual que en Temblor de cielo en cuyos versos "la tiniebla vuelve a la luz" a través de la garganta del hablante, en el extracto de "Las voces preciosas", antes transcrito, la garganta del hablante filtra el "gran caos de palabras ciegas" que contiene la muerte. Asimismo, esa garganta ensaya un idioma hecho "de vapores", o sea, un idioma en formación con deslindes imprecisos y vagos. El hablante, bajo la figura de un "recién muerto" o de un "mendigo en el infinito" resume la idea del carácter de novicio que aún tiene en el proceso de resignificación escatológica o quizá se está percatando de la imposibilidad que implica transferir los significados coherentemente desde el campo semántico de la muerte al de la vida. Y esta idea admite ser complementada con títulos como el del penúltimo poema: "Campo de experimentación".

El ciudadano del olvido es el título que el poeta le da a su último libro publicado en vida y es bastante decidor. El hablante lírico continúa hablando desde la muerte pero, a la vez, su discurso comienza a desvanecerse más allá de su muerte, en el olvido de quienes lo escuchan desde la vida. En "Preludio de esperanza" se recalca:

Cantas y cantas hablas y hablas

Y ruedas por el tiempo 


\section{Y lloras como lirio desatado}

Y suspiras entre largos agonizantes que no saben qué decir [...]

Cantas y cantas hablas y hablas

$\mathrm{Y}$ te olvidas de todo para que todo te olvide $(501,502)$.

Esta obra es bastante extensa y contiene mayormente poemas en verso combinados con algunos poemas en prosa. La sola palabra "muerte", sin derivados, se repite sesenta y siete veces. La temática escatológica es abrumadora y con afán sintético rescato los siguientes versos del poema "Comaruru"8 :

Debéis saber que nada es imposible

Y que bien puede ser la palabra de un muerto [...]

Decid al cadáver que se aleje con la muerte al hombro

Decid a la muerte que esconda sus cadáveres

Así iréis muriendo con la boca abierta

Esperando con la boca abierta la palabra que cae del cielo

La palabra que viene cayendo del cielo para que la descifréis

Con el sentido oculto debajo de una piedra

Y el ritmo de la sangre de un poeta remoto $[\ldots]$

Para decir grandes cosas hay que morir primero [...]

Voy a unirme a mis palabras

Y entonces me perderé de vista a vuestros ojos

Nadie sabrá de mí

Yo estaré adentro de mis palabras

$\mathrm{Y}$ el nacimiento de un grito que va haciendo olas

Y no tiene límite porque vosotros no conocéis sus límites

Ni el nombre de la estrella que se irá inflando con mi voz (510, 511).

Las palabras que vienen emitidas desde el más allá tienen un "sentido oculto" y deben ser "descifradas". Hay problemas de comunicación entre el emisormuerto y el receptor-vivo y el primero toma conciencia de su alejamiento. Se evidencia que el hablante lírico tiene una sobrevida indeterminada después de la muerte que lo transfigura en hablante escatológico para emitir

\footnotetext{
$8 \quad$ Transcribo íntegramente la cita al pie de página (quizá la única en toda su obra poética) que el mismo autor consignó en este título: "Coincidiendo con el pasaje del planeta Marte en su mayor proximidad a la Tierra, hacia 1927, algunos investigadores enviaron un mensaje radial a dicho astro, con la esperanza de que esta comunicación fuera interceptada y contestada por los presuntos habitantes de Marte. Como respuesta, las antenas de las estaciones del Brasil recogieron unos sonidos que correspondían a la palabra Comaruru”.
} 
prometeicamente su personal teofanía y finalmente, se disuelve, mediante un sorpresivo giro agnóstico, en el olvido y la nada.

A modo de conclusión podemos señalar que la tradicional distinción entre la etapa modernista y creacionista no es suficiente para captar cabalmente la estética metafísica que nos brinda la obra poética de Huidobro. Pecará también de incompleto, para una verdadera comprensión de la resignificación escatológica que dicha estética contiene, el análisis parcial y por separado de cada una de sus obras. Se hace necesario abordar su obra poética completa para entender que estamos ante un opus huidobriano de la muerte que sigue una secuencia diacrónica coherente y seria, tal como lo confirma Orlando Jimeno cuando sostiene que "[1]a vastísima semiosis del opus huidobreano exige una lectura estructuralmente semántica de vastos segmentos de su obra total" (1477). Aplicando dicho orden de lectura, toda la etapa modernista de Huidobro y parte de la creacionista (hasta Poemas árticos) nos brinda un sujeto lírico que descubre a la muerte como un lugar de enunciación inaudito, reconociendo, a su vez, que aún es incapaz para emitir su discurso desde allí. Desde Altazor (ya en la plenitud del creacionismo) el sujeto sufre diversas mutaciones hasta su final transfiguración en eternauta, investido como sujeto de enunciación habilitado para emitir su particular teofanía. La figura del palíndromo es la clave que permite el tránsito de su discurso a través del umbral de la muerte. Con ello se estructura una poética escatológica, sin duda, heterodoxa. En la obra poética tardía del poeta, Ver y palpar y El ciudadano del olvido, el hablante-eternauta sufre un proceso irreversible de incomunicación, una falla técnica de sintaxis que impide la reconfiguración semántica del lenguaje, conduciéndolo al hermetismo y finalmente a la nada.

\section{BIBLIOGRAFÍA}

Binns, Niall. Nicanor Parra o el arte de la demolición. Valparaíso, Chile: Editorial UV de la Universidad de Valparaíso, 2014.

Concha, Jaime. "Altazor de Vicente Huidobro". Obra poética de Vicente Huidobro. México: Fondo de Cultura Económica / Ediciones UNESCO / ALLCA Siglo XX (2003): 1585-1598.

Cuneo, Ana María. “Análisis de "El espejo de agua”, poema de Vicente Huidobro”. Revista Chilena de Literatura 8 (1977): 67-82.

De Costa, René. En pos de Huidobro. Siete ensayos de aproximación. Santiago: Editorial Universitaria, 1980. 
Diccionario Akal de Filosofía. Madrid: Ediciones Akal S.A., 2004. En línea: https:// holismoplanetario.files.wordpress.com/2009/07/audi-robert-diccionario-akal-de-filosofia.pdf Eliade, Mircea. El mito del eterno retorno. Buenos Aires: Emecé editores, 2001. Lo sagrado y lo profano. Barcelona: Paidos, 1998.

Goic, Cedomil. “Altazor, de Vicente Huidobro”. Obra poética de Vicente Huidobro. México: Fondo de Cultura Económica / Ediciones UNESCO / ALLCA Siglo XX (2003): 1598-1603.

Hahn, Oscar. Prólogo a la edición de Altazor publicada por Editorial Universitaria. Santiago, 1997.

Huidobro, Vicente. Obras completas. Santiago: Zig-Zag editores, 1964.

Jimeno, Orlando. "Modernidad y fragmentación de la conciencia en Temblor de cielo". Anales de literatura chilena, año 4, número 4, 2003.

López, Berta. “Altazor: hacia una verticalización de la épica”. Revista Chilena de Literatura 14 (1979): 21-54.

Montes, Hugo. "Altazor a la luz de los religioso". Revista Chilena de Literatura 18 (1981): 35-46.

Tamayo, Juan José. Nuevo diccionario de Teología. Madrid: Editorial Trotta, 2005. 